\title{
Insulin Effect on Gene Expression of Dental Pulp Cell during Osteodifferentiation
}

\author{
Fidan Huseynova ${ }^{1,2}$, Alamdar Mammadov², Irada Huseynova ${ }^{2}$, Frédéric Cuisinier ${ }^{1}$, \\ Véronique Barragan-Montero ${ }^{1}$
}

${ }^{1}$ LBN, University Montpellier, Montpellier, France

${ }^{2}$ Institute Molecular Biology and Biotechnology of ANAS, Baku, Azerbaijan

Email: fidan.huseynova@etu.umontpellier.fr, vvell.fidan.huseynova92@gmail.com,amamedov_ib@yahoo.co.uk,

i_guseinova@mail.ru,frederic.cuisinier@umontpellier.fr, veronique.montero@umontpellier.fr

How to cite this paper: Huseynova, F., Mammadov, A., Huseynova, I., Cuisinier, F. and Barragan-Montero, V. (2022) Insulin Effect on Gene Expression of Dental Pulp Cell during Osteodifferentiation. Journal of Biosciences and Medicines, 10, 99-107. https://doi.org/10.4236/jbm.2022.101009

Received: December 1, 2021

Accepted: January 21, 2022

Published: January 24, 2022

Copyright ( 2022 by author(s) and Scientific Research Publishing Inc. This work is licensed under the Creative Commons Attribution International License (CC BY 4.0).

http://creativecommons.org/licenses/by/4.0/

\begin{abstract}
Insulin, an old but still actual molecule, has many roles in various cellular processes including bone formation and also angiogenesis. Insulin effects on different cell types were investigated, and we intended to check its effect on dental pulp cells (DPC) during osteoblast differentiation. First, bone differentiation ability of isolated dental pulp cells was assessed by alizarin red (AR) staining. Insulin increased dental pulp cell proliferation after 25 hours of culture. It increased mRNA expression of osteogenic markers such as Col1, RunX2, ALP, Osc, Mef2C and expression of genes involved in TGF $b$ pathway such as Smad3, TSP1, VEGF at different time points.
\end{abstract}

\section{Keywords}

Dental Pulp Cells, Gene Expression, Osteodifferentiation, Insulin

\section{(c) (i) Open Access}

\section{Introduction}

Insulin is an anabolic molecule secreted by the beta cells of pancreas Langerhans islets. It plays an important role in glucose homeostasis which is its primary role. In addition to primary effect, it also promotes a variety of other cellular events such as glycogen synthesis, lipid metabolism, regulation of ion and amino acid transport, gene transcription mRNA turnover, synthesis and degradation of proteins, and DNA synthesis. Thus it has a key role in cell metabolism, cell survival, cellular growth, proliferation, and differentiation [1] [2] [3]. In normal physiological conditions, the stimulation and kinetics of insulin secretion are happened under circadian rhythm, with higher levels in the hepatic portal than 
in the peripheral circulation. By contrast, injected insulin seeps into the common circulation, exposing all tissues to an equal concentration of molecule for a prolonged time period, leading to the development of a nexus of metabolic and cardiovascular complications which is observed as a part of the side effects of molecule. But, there are developed intelligent stimuli-responsive hydrogel delivery systems in order to release insulin in a pulsatile manner in response to glucose concentration [4]. Insulin acts by binding to its receptor (IR) as well as IGF1 receptor. IR gene is located on the short arm of chromosome 19, with about 150 kilobase pairs in length involving 22 exons and 21 introns. The promoter contains many binding sites for transcription factors such as CAAT/enhancer-binding protein, Spl, NF-1, defining its role in cellular processes including differentiation [3]. Insulin receptors are present on both osteoblasts (preand mature-) and endothelial cells, making these cells sensitive to the hormone. However cells from the retinal capillaries were responsive to insulin whereas endothelial cells from large arteries were not. But to fully understand the physiological role of insulin, it is necessary to identify its action, at the molecular level, the key components in the insulin-signaling pathway. It binds to IGF1-R as well as we mentioned, leading to stimulation of IGF1 pathway, which this pathway has a regulating role in, wound healing and cell growth [5] [6] [7]. It was shown that insulin promotes osteoblast differentiation through the MAPK and PI3K pathways. It upregulates Osx and IGF1 expression, ALP activity, RunX2 and collagen expression in MG-63 cells (10 nM) [8]. It increases the amount of TGF- $\beta$ receptors at the mouse embryonic fibroblasts and NMuMG epithelial cells surface (by their translocation from plasma to cell membrane), thereby enhancing TGF- $\beta$ responsiveness, and thus enables insulin to increase TGF- $\beta$-induced gene responses [9]. The TGF- $\beta$ pathway is important for both bone formation and angiogenesis. It induces osteodifferentiation of umbilical cord's mesenchymal stem cells on PLLA (Poly-L-Lactic-Acid) polymer scaffold at different concentrations. In fact, insulin needs to have glucose in its environment. At low glucose concentration, it can't interact with its receptors, which leads to the inhibition of growth and differentiation [10]. On the other hand, it was reported that insulin induces VEGF expression in endothelial cells, but high glucose condition attenuates this effect and reduces VEGF expression [11]. It was demonstrated that synovial fluid contains high amounts of insulin, and thus induces cell proliferation, viability and chondrogenic differentiation of MSCs [12]. Taking into account all the mentioned works we intended to check insulin effect on gene expression involved in TGF $\beta$ pathway during osteodifferentiation of dental pulp cells.

\section{Methods}

\subsection{Dental Pulp Cells}

Dental pulp cells were isolated from extracted third molars of healthy patients after informed consent. Protocol was approved by the local ethical committee 
(Comité de Protection des Personnes, Montpellier Hospital, France). The tooth was divided to two pieces under weak flow of $2 \%$ chlorhexidine 600079 , Pierre Fabre). The obtained pulp tissue was digested using $3 \mathrm{mg} / \mathrm{ml}$ collagenase type I (Cas No. 9001-12-1, Gibco) and 4 mg/ml dispase (Cat. No. 17105-041, Gibco) solution for $1 \mathrm{~h}$ at $37^{\circ} \mathrm{C}$. After filtration through $70-\mu \mathrm{m}$ Falcon strainers, cells were let to incubate in $\alpha \mathrm{MEM}$ media supplemented with $10 \%$ fetal bovine serum (FBS), $100 \mathrm{U} / \mathrm{ml}$ penicillin, $100 \mu \mathrm{g} / \mathrm{ml}$ streptomycin. After $24 \mathrm{~h}$ non-adherent cells were removed by washing and cells were incubated for 1 week at $37^{\circ} \mathrm{C}$, $5 \% \mathrm{CO}_{2}$.

\subsection{Osteodifferentiation and Alizarin Red (AR) Staining}

To prove the differentiation ability of isolated dental pulp cells to osteoblast lineage, cells at passage 7 were seeded at 500,000 cell $/ \mathrm{ml}$ and, after attachment, were cultured either with basal medium ( $\alpha$ MEM supplemented with $10 \%$ fetal bovine serum (FBS), $100 \mathrm{U} / \mathrm{ml}$ penicillin, $100 \mu \mathrm{g} / \mathrm{ml}$ streptomycin) or either with osteomedium (OM: basal medium supplemented with glycerophosphate, 1-ascorbate acid, and $10 \mathrm{nM}$ dexamethasone) for 3 weeks.

After 3 weeks, AR staining and Colorimetric measurement were performed. Cells were washed with PBS, fixed with ethanol then washed with distilled $\mathrm{H}_{2} \mathrm{O}$ and incubated with alizarin red solution. Excessive dye was removed by washing with distilled $\mathrm{H}_{2} \mathrm{O}$ for 3 - 4 times. Then binding calcium ions were dissolved in cetylpyridinium chloride solution for $15 \mathrm{~min}$ under agitation. Then calcium deposition was determined by spectrophotometry at $562 \mathrm{~nm}$ wavelength.

\subsection{MTT Assay}

MTT(3-(4,5-dimethylthiazol-2-yl)-2,5-diphenyltetrazolium bromide) assay was performed at 16 and 25 hours to assess cell viability. 10,000 cells/per well were seeded on 96 well-plate. Cells were incubated with MTT solution at $1 \mathrm{mg} / \mathrm{ml}$ concentration, followed by the addition of $100 \mu \mathrm{l}$ of isopropanol to solve formazan crystals. Spectrophotometric measurement was carried out at $540 \mathrm{~nm}$ (ELX 800, BioTek, Winooski, USA). (Experiment was carried out in pentaplicate).

\subsection{Quantitative RT-PCR}

In order to compare the relative expression of osteogenesis-related genes, qRT-PCR analysis was performed after treatment with $200 \mathrm{ng} / \mathrm{ml}$ insulin. Total RNA was extracted from DPSC at 1 or 2 weeks of culture using Machery Nager reagent according to the manufacturing instruction. The quantity and quality of RNA were assessed by nanodrop and bioanalyzer. cDNA was synthesized from samples using RevertAid First Strand cDNA Synthesis Kit (K1622) from Thermo scientific. QRT-PCR was performed on a LightCycler (Applied Biosystems) for the following genes described in Table 1. mRNA expression was evaluated by LightCycler480 Software and expressed as $2-\Delta \mathrm{Ct}$ value. Analysis was normalized to the GAPDH housekeeping gene. 
Table 1. The primer sequences for the indicated genes.

\begin{tabular}{|c|c|}
\hline Gene name & Sequence \\
\hline Col1 & $\begin{array}{l}>\text { FW AGAACTGGTACATCAGCAAG } \\
>\text { RW GAGTTTACAGGAAGCAGACA }\end{array}$ \\
\hline ALP & $\begin{array}{c}\text { >FW CCAACGTGGCTAAGAATGTCATC } \\
>\text { RW TGGGCATTGGTGTTGTACGTC }\end{array}$ \\
\hline RunX2 & $\begin{array}{l}\text { >FW TGGTTAATCTCCGCAGGTCAC } \\
>\text { RW ACTGTGCTGAAGAGGCTGTTTG }\end{array}$ \\
\hline Smad3 & $\begin{array}{l}>\text { FW AAGTGCATCACCATCCCCAG } \\
>\text { RW GGGTCAACTGGTAGACAGCC }\end{array}$ \\
\hline TSP1 & $\begin{array}{l}\text { >FW AAGACCTGGTGGATGCTGTG } \\
>\text { RW GAAGACGCTTTGGATGGGGA }\end{array}$ \\
\hline VEGFA & $\begin{array}{l}>\text { FW CCATCCAATCGAGACCCTGG } \\
>\text { RW TATGTGCTGGCCTTGGTGAG }\end{array}$ \\
\hline Osc & $\begin{aligned} &>\text { FW CCATGAGAGCCCTCACACTCC } \\
&>\text { RW GGTCAGCCAACTCGTCACAGTC }\end{aligned}$ \\
\hline $\mathrm{Mef} 2 \mathrm{C}$ & $\begin{array}{l}\text { >FW GCACCAACAAGCTGTTCCAG } \\
>\text { RW TGTCTGAGTTTGTCCGGCTC }\end{array}$ \\
\hline TGFb1 & $\begin{array}{l}\text { >FW TGAACCGGCCTTTCCTGCTTCTCAT } \\
>\text { RW GCGGAAGTCAATGTACAGCTGCCGC }\end{array}$ \\
\hline TFFb1R & $\begin{array}{l}\text { >FW TGAACCGGCCTTTCCTGCTTCTCATG } \\
>\text { RW GCGGAAGTCAATGTACAGCTGCCGC }\end{array}$ \\
\hline TGFb2 & $\begin{array}{l}>\text { FW GGCTCAACCACCAGGGCATCCAGAT } \\
>\text { RW CTCCCCGAGAGCCTGTCCAGATGCT }\end{array}$ \\
\hline GAPDH & $\begin{array}{l}\text { >FW ATGGGGAAGATAAAGGTCG } \\
>\text { RW TAAAAGCAGCCCTGGTGACC }\end{array}$ \\
\hline
\end{tabular}

\subsection{Statistical Analysis}

Data were analyzed by GraphPad Prism7 (GraphPad Software, Inc., La Jolla, USA). Statistical analysis was performed by One way Anova, and parametric or non-parametric t-test depending on the Shapiro-Wilk test result. $\mathrm{p}<0.05$ was considered significant.

\section{Results}

\subsection{Osteodifferentiation of DPC}

Calcium deposition was checked after 3 weeks of dental pulp cell culture in osteomedium (test) or basal medium (control). The obtained data (Figure 1) obviously show the differentiation ability of DPCs to osteogenic lineage. $\mathrm{P}=0.0049$.

\subsection{MTT Assay}

At 16 and 25 hours of culture, MTT assay was performed to check cell viability (Figure 2). $200 \mathrm{ng} / \mathrm{ml}$ of insulin has a significantly higher effect $(\mathrm{p}=0.02)$ than control at $25 \mathrm{~h}$ and over $100 \mathrm{ng} / \mathrm{ml}$ insulin $(\mathrm{p}=0.02)$, however, there was no significant difference after $16 \mathrm{~h}$ of culture. $\mathrm{n}=5$. 

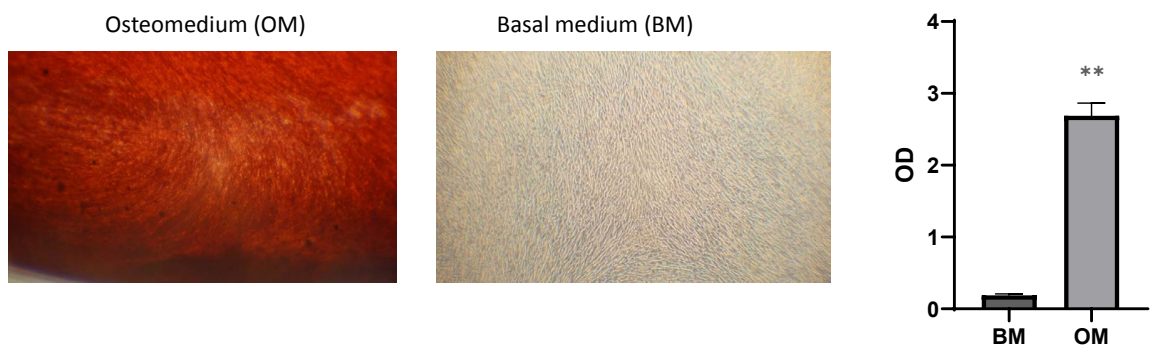

(a)

(b)

Figure 1. Optical microscopic images of differentiation assays. (a) AR staining of DPC cultures after 21 days in osteogenic medium (OM) and in basal medium (BM); (b) Optical dentsitometry. Note the calcium deposition in cells cultured in OM. ${ }^{* *}$ indicates $\mathrm{p}<$ 0.01 and was considered as a significant statistical difference.

MTT 16 h

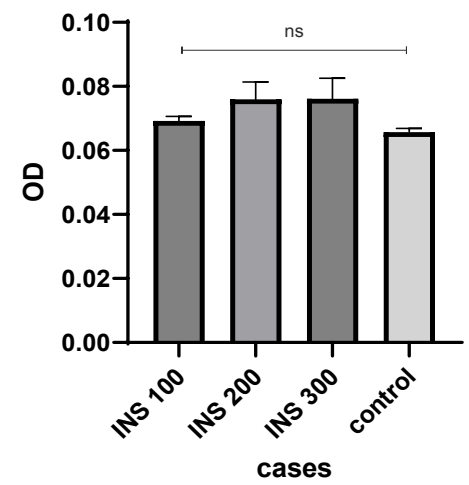

MTT 25h

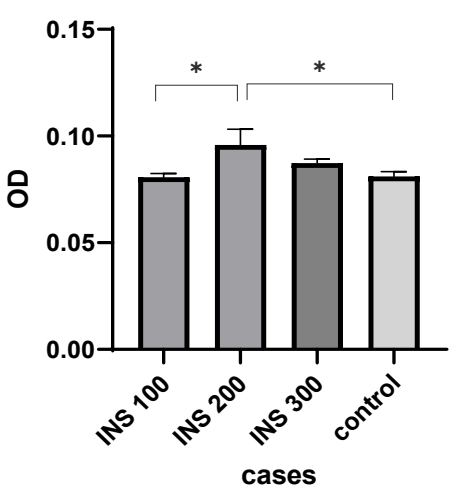

Figure 2. MTT test. Comparison of $100 \mathrm{ng} / \mathrm{ml} ; 200 \mathrm{ng} / \mathrm{ml}$ and $300 \mathrm{ng} / \mathrm{ml} \mathrm{in}$ sulin effect on cell viability. ${ }^{*}$ indicates $\mathrm{p}<0.05$ and was considered as a significant statistical difference.

\subsection{RT-qPCR}

At 7 or 14 days of differentiation 11 genes were evaluated by RT-qPCR (Figure 3). The obtained data revealed that TGFb mRNA expression at day $7(\mathrm{p}=0.03)$, TGFbR1 at day $7(\mathrm{p}=0.03)$, TGFb2 at day $7(\mathrm{p}=0.03)$; Col1 at day $7(\mathrm{p}=0.17)$, at day $14(\mathrm{p}=0.03)$, ALP at day $7(\mathrm{p}=0.03)$, RunX2 at day $7(\mathrm{p}=0.47)$, at day 14 $(\mathrm{p}=0.96)$; Osc at day $7(\mathrm{p}>0.9)$, at day $14(\mathrm{p}-0.56)$; Smad3 at day $7(\mathrm{p}=0.24)$, at day $14(\mathrm{p}=0.08)$; TSP1 at day $7(\mathrm{p}=0.03)$; VEGFA at day $7(\mathrm{p}=0.03)$; MEF2C at day 7 ( $\mathrm{p}=0.21)$; was increased after insulin treatment. It also has an increasing effect on Smad3, but not significantly $(p=0.077)$.

\section{Discussion}

Insulin signaling has a role in bone development both via osteoblast and osteoclast development. Impaired bone quality is related to impair osteoblastic insulin signaling. However, IR (insulin receptor) exists both in osteoblasts and osteoclasts but it acts in bone development by means of osteoblastic proliferation and 
TGFb1

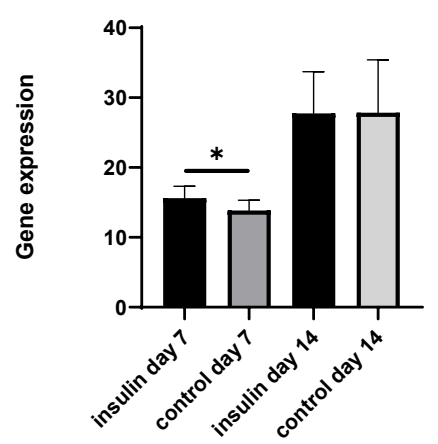

Col1

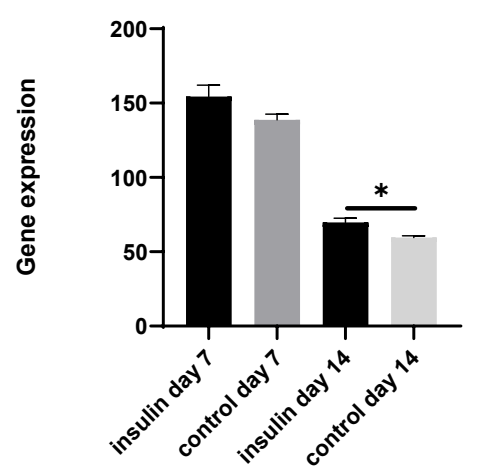

Osc

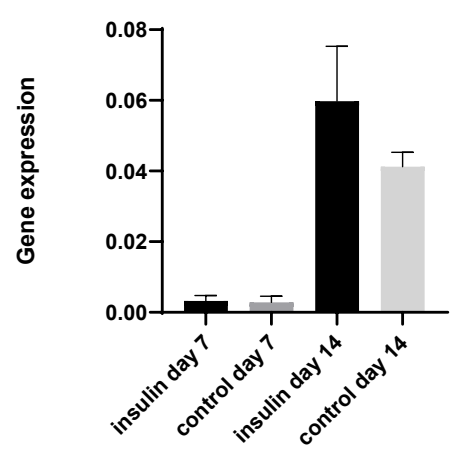

VEGFA

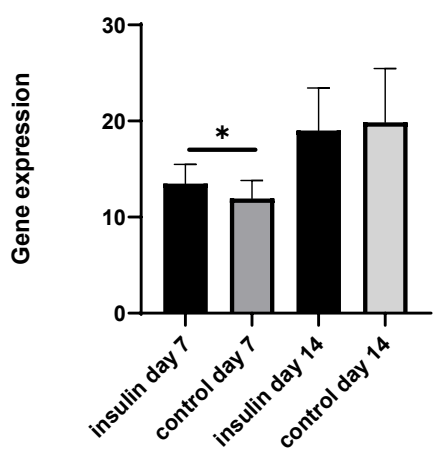

TGFbR1

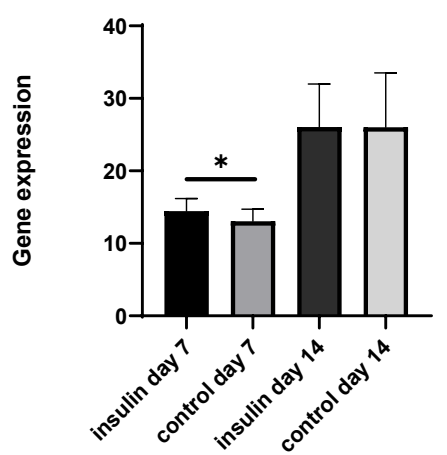

ALP

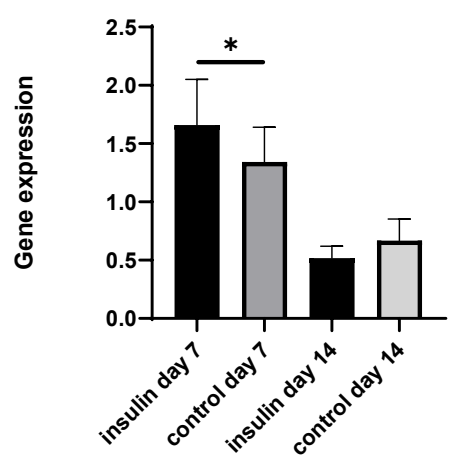

MEF2C

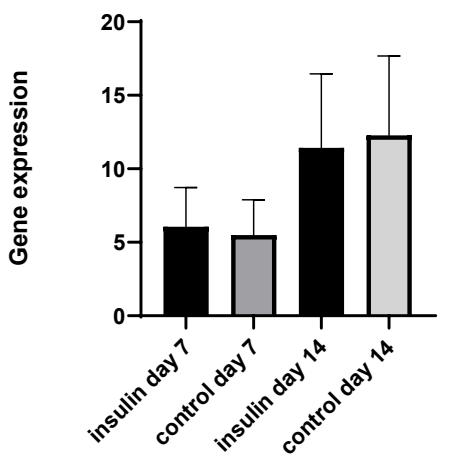

Smad3

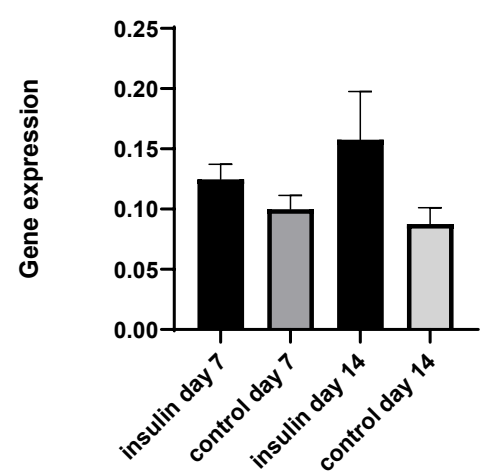

TGFb2

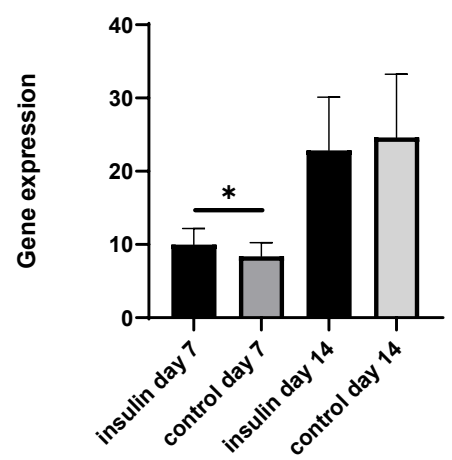

RunX2

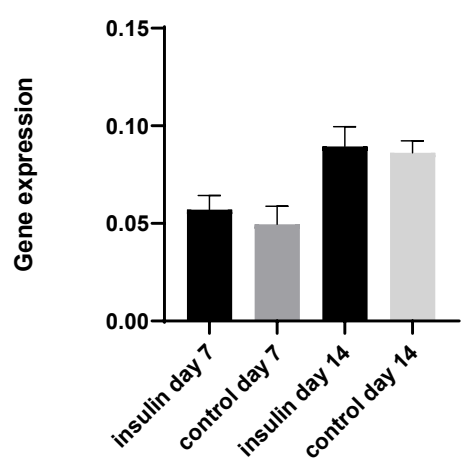

TSP1

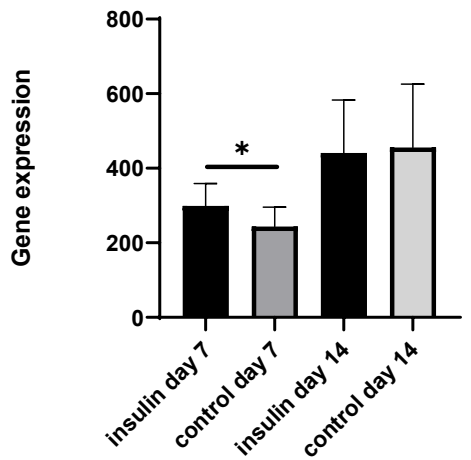

Figure 3. Insulin effect on TGFb, TGFbR1, TGFb2, Col1, ALP, RunX2, Smad3, TSP1, VEGFA, Mef2C mRNA expression during osteodifferentiation. T-test was conducted as statistical analysis, $\mathrm{p}<0.05$ was considered significant. (Experiment was conducted in triplicate, $\mathrm{n}=2$ ). ${ }^{*}$ indicates $\mathrm{p}<0.05$ and was considered as a significant statistical difference. 
RunX2 expression through M6PK/PI3K pathways [13]. RunX2 is a transcription factor having many target genes including Col1a2, osteocalcin, matrix metalloproteinase-9, integrin-binding sialoprotein, Akp2, Dmp1, Phex, Vdr, osterix, etc., which decreased in insulin-deficient diabetic animals and restored in insulin-treated animals [14]. In this study, we observed enhanced RunX2, Col1, ALP expression during osteodifferentiation on DPSC after $200 \mathrm{ng} / \mathrm{ml}$ insulin treatment and showed an enhanced effect on the expression of osteogenic markers as well on proliferation. There was information that insulin enhances TGFb receptors in the cell membrane by their translocation (as mentioned above), but in this study, we also showed that $200 \mathrm{ng} / \mathrm{ml}$ concentration of insulin significantly enhances TGFbR1, and also TGFb, TGFb2 in mRNA level during osteodifferentiation of DPSC at 7 days of culture. In the same time a decreased effect under $100 \mathrm{ng} / \mathrm{ml}$ insulin as described in literature after $24 \mathrm{~h}$ and $47 \mathrm{~h}$ of DPSC culture (but not under osteogenic condition), for the TGFb1, TGFb2, TGFbR1, TGFbR2 genes (not significantly), but an enhanced effect for the BMP3, BMP4, BMPR1A genes was reported [15]. It was shown that TGFb1 treatment $(10 \mathrm{ng} / \mathrm{ml}$, for 2 days) increases osteodifferentiation by mineralized matrix, reorganizing the actin cytoskeleton, and through many osteogenic genes including RunX2, ALP, Osc [16]. At one week of osteodifferentiation, the genes involved in TGF $\beta$ pathway such as Smad3, VEGFA, TSP1, and additionally Mef2C expression are upregulated. TSP1 is also an extracellular matrix protein and is expressed abundantly during osteodifferentiation. It is one of the proteins that regulate bone homeostasis. It decreased osteoclast (OC) activity and OC differentiation, and regulates the osteoblast-osteoclast balance, however its role in bone homeostasis is ambiguous [17]. It is antiangiogenic but also is one of the main activators of TGF- $\beta 1$ (by preventing its latency-associated peptide from deactivating the mature domain of TGF- $\beta 1$ [18] [19], leading to the induction of VEGF-A parallelly in the same pathway as a well-balanced process, which is in accordance to our results. Insulin also enhances TGF- $\beta$-induced angiogenesis by Smad2/3, and inhibition of this pathway inhibits angiogenesis as well [20]. We didn't reveal a significant difference for MeF2C which has an induction effect on bone development, but a suppressing effect on angiogenesis [21] [22].

\section{Conclusion}

We concluded that insulin induces DPC proliferation and osteogenic differentiation through many osteogenesis-related genes at the mRNA level. Insulin is an angiogenic molecule as well as an osteogenic one. It may be a good candidate for bone regeneration strategies even if it has side effects in a non-diabetic patients., However, its half-circulating life is short but a number of insulin delivery systems such as PLGA (poly (lactic-co-glycolic acid), hydroxyapatite (HA), alginate, gelatin, ( $\gamma$-glutamic acid)/ $\beta$-tricalcium phosphate, $\gamma$-PGA/ $\beta$-TCP), chitosan, etc., have been developed to increase the absorption of this molecule [23]. It may be interesting to look for a way to use insulin to benefit from its regenera- 
tive effect, maybe with the combination of other molecules in order to limit its side effect such as hypoglycemia as excess amounts of glucose are being removed from the blood.

\section{Acknowledgements}

F.H. acknowledges Ph.D. grant from the Azerbaijan National Academy of Sciences (ANAS) and the French Ministry of Education (2018-2020) and the Ministry of Education of Azerbaijan Republic (2021-2022).

\section{Conflicts of Interest}

The authors declare no conflicts of interest regarding the publication of this paper.

\section{References}

[1] Wilcox, G. (2005) Insulin and Insulin Resistance. Clinical Biochemistry, 26, 19-39.

[2] Manchester, K.L., et al. (1972) Effect of Insulin on Protein Synthesis. Diabetes, 21, 447-452. https://doi.org/10.2337/diab.21.2.S447

[3] Cheatham, B. and Kahn, C.R. (1995) Insulin Action and the Insulin Signaling Network. Endocrine Reviews, 16, 117-142. https://doi.org/10.1210/edrv-16-2-117

[4] Pillai, O. and Panchagnula, R. (2001) Insulin Therapies-Past, Present and Future. Drug Discovery Today, 6, 1056-1061. https://doi.org/10.1016/S1359-6446(01)01962-6

[5] Thomas, D.M., Hards, D.K., Rogers, S.D., Ng, K.W. and Best, J.D. (1996) Insulin Receptor Expression in Bone. Journal of Bone and Mineral Research, 11, 1312-1320. https://doi.org/10.1002/jbmr.5650110916

[6] Jalal, I., Cretaz, M. and Hachiya, H.L. (1985) Characterization of the Receptors for Insulin and the Insulin-Like Growth Factors on Micro- and Macrovascular Tissues. Endocrinology, 117, 1222-1229. https://doi.org/10.1210/endo-117-3-1222

[7] Sarenac, T., Trapecar, M., Gradisnik, L., Rupnik, M.S. and Pahor, D. (2016) Single-Cell Analysis Reveals IGF-1 Potentiation of Inhibition of the TGF- $\beta / \mathrm{Smad}$ Pathway of Fibrosis in Human Keratocytes in Vitro. Scientific Reports, 6, Article No. 34373. https://doi.org/10.1038/srep34373

[8] Yang, J., Zhang, X., Wang, W. and Liu, J. (2010) Insulin Stimulates Osteoblast Proliferation and Differentiation through ERK and PI3K in MG-63 Cells. Cell Biochemistry and Function, 28, 334-341. https://doi.org/10.1002/cbf.1668

[9] Budi, E.H., Muthusamy, B. and Derynck, R. (2015) The Insulin Response Integrates Increased TGF-b Signaling through Akt-Induced Enhancement of Cell Surface Delivery of TGF-b Receptors. Cell Biology, 8, 2-15. https://doi.org/10.1126/scisignal.aaa9432

[10] Pasban, E., Oryan, S., Asadi, A., Eidi, A. and Mansourizade, F. (2014) Effect of Insulin on Umbilical Cord's Mesenchymal Stem Cells on PLLA Polymer Scaffold. Journal of Applied Environmental and Biological Sciences, 4, 129-136.

[11] Wu, H., Xia, X. and Jiang, C. (2010) High Glucose Attenuates Insulin-Induced VEGF Expression in Bovine Retinal Microvascular Endothelial Cells. Eye (London, England), 24, 145-151. https://doi.org/10.1038/eye.2009.157

[12] Soleimani, S., Nazem, H., Fazilati Modarres, M. and Atyabi, S.M. (2018) Effect of 
Synovial Fluid Insulin Rate on Mesenchymal Stem Cells Differentiation to Chondrocyte. MOJ Biology and Medicine, 3, 53-56.

https://doi.org/10.15406/mojbm.2018.03.00076

[13] Pramojanee, S.N., Phimphilai, M., Chattipakorn, N. and Chattipakorn, S.C. (2014) Possible Roles of Insulin Signaling in Osteoblasts. Endocrine Research, 39, 144-151. https://doi.org/10.3109/07435800.2013.879168

[14] Fowlkes, J.L., Bunn, R.C., Liu, L., et al. (2008) Runt-Related Transcription Factor 2 (RUNX2) and RUNX2-Related Osteogenic Genes Are Down-Regulated throughout Osteogenesis in Type 1 Diabetes Mellitus. Endocrinology, 149, 1697-1704. https://doi.org/10.1210/en.2007-1408

[15] Lauritano, D., Avantagiato, A., Candotto, V., Cura, F., Gaudio, R.M., Martinelli, M. and Palmieri, A. (2015) Insulin Activity on Dental Pulp Stem Cell Differentiation: An in Vitro Study.

[16] Elsafadi, M., Manikandan, M., Almalki, S., et al. (2018) TGF $\beta 1$-Induced Differentiation of Human Bone Marrow-Derived MSCs Is Mediated by Changes to the Actin Cytoskeleton. Stem Cells International, 2018, Article ID: 6913594.

https://doi.org/10.1155/2018/6913594

[17] Amend, S.R., Uluckan, O., Hurchla, M., et al. (2015) Thrombospondin-1 Regulates Bone Homeostasis through Effects on Bone Matrix Integrity and Nitric Oxide Signaling in Osteoclasts. Journal of Bone and Mineral Research: The Official Journal of the American Society for Bone and Mineral Research, 30, 106-115. https://doi.org/10.1002/jbmr.2308

[18] Schultz-Cherry, S., Ribeiro, S., Gentry, L. and Murphy-Ullrich, J.E. (1994) Thrombospondin Binds and Activates the Small and Large Forms of Latent Transforming Growth Factor-Beta in a Chemically Defined System. Journal of Biological Chemistry, 269, 26775-26782. https://doi.org/10.1016/S0021-9258(18)47086-X

[19] Crawford, S.E., Stellmach, V., Murphy-Ullrich, J.E., et al. (1998) Thrombospondin-1 Is a Major Activator of TGF- $\beta 1$ in Vivo. Cell, 93, 1159-1170. https://doi.org/10.1016/S0092-8674(00)81460-9

[20] Budi, E.H., Mamai, O., Hoffman, S., Akhurst, R.J. and Derynck, R. (2019) Enhanced TGF- $\beta$ Signaling Contributes to the Insulin-Induced Angiogenic Responses of Endothelial Cells. iScience, 11, 474-491. https://doi.org/10.1016/j.isci.2018.12.038

[21] Arnold, M.A., Kim, Y., Czubryt, M.P., et al. (2007) MEF2C Transcription Factor Controls Chondrocyte Hypertrophy and Bone Development. Developmental Cell, 12, 377-389. https://doi.org/10.1016/j.devcel.2007.02.004

[22] Stephens, A.S., Stephens, S.R., Hobbs, C., et al. (2011) Myocyte Enhancer Factor 2c, an Osteoblast Transcription Factor Identified by Dimethyl Sulfoxide (DMSO)-Enhanced Mineralization. The Journal of Biological Chemistry, 286, 30071-30086. https://doi.org/10.1074/jbc.M111.253518

[23] Zhang, X., Xing, H., Qi, F., Liu, H., Gao, L. and Wang, X. (2020) Local Delivery of Insulin/IGF-1 for Bone Regeneration: Carriers, Strategies, and Effects. Nanotheranostics, 4, 242-255. https://doi.org/10.7150/ntno.46408 